\title{
Combined Lymphedema and Capillary Malformation of the Lower Extremity
}

\section{Citation}

Maclellan, Reid A., Gulraiz Chaudry, and Arin K. Greene. 2016. "Combined Lymphedema and Capillary Malformation of the Lower Extremity." Plastic and Reconstructive Surgery Global Open 4 (2): e618. doi:10.1097/G0X.0000000000000487. http://dx.doi.org/10.1097/ GOX.0000000000000487.

\section{Published Version}

doi:10.1097/GOX.0000000000000487

\section{Permanent link}

http://nrs.harvard.edu/urn-3:HUL.InstRepos:26318765

\section{Terms of Use}

This article was downloaded from Harvard University's DASH repository, and is made available under the terms and conditions applicable to Other Posted Material, as set forth at http:// nrs.harvard.edu/urn-3:HUL.InstRepos:dash.current.terms-of-use\#LAA

\section{Share Your Story}

The Harvard community has made this article openly available.

Please share how this access benefits you. Submit a story.

\section{Accessibility}




\section{Combined Lymphedema and Capillary Malformation of the Lower Extremity}

\author{
Reid A. Maclellan, MD, \\ MMSc* \\ Gulraiz Chaudry, MBChB, \\ FRCR $†$
}

Arin K. Greene, MD, MMSc*
Background: Primary lymphedema and capillary malformation are independent vascular malformations that can cause overgrowth of the lower extremity. We report a series of patients who had both types of malformations affecting the same leg. The condition is unique but may be confused with other types of vascular malformation overgrowth conditions (eg, Klippel-Trenaunay and Parkes Weber).

Methods: Our Vascular Anomalies Center and Lymphedema Program databases were searched for patients with both capillary malformation and lymphedema. Diagnosis of lymphedema-capillary malformation was made by history, physical examination, and imaging studies. Because lymphedema-capillary malformation has phenotypical overlap with other conditions, only patients who had imaging confirming their diagnosis were included in the analysis. Clinical and radiological features, morbidity, and treatment were recorded.

Results: Eight patients ( 4 females and 4 males) had confirmed lymphedemacapillary malformation. Referring diagnosis was Klippel-Trenaunay syndrome $(n=4)$, diffuse capillary malformation with overgrowth $(n=3)$, or lymphatic malformation $(n=1)$. The condition was unilateral $(n=6)$ or bilateral $(n=2)$. Morbidity included infection $(n=6)$, difficulty fitting clothes $(n=6)$, bleeding or leaking vesicles $(n=5)$, leg length discrepancy $(\mathrm{n}=4)$, and difficulty ambulating $(\mathrm{n}=3)$. All patients were managed with compression regimens. Operative management was liposuction $(\mathrm{n}=3)$, treatment of phlebectatic veins $(n=3)$, staged skin/subcutaneous excision $(\mathrm{n}=1)$, and/or epiphysiodesis $(\mathrm{n}=1)$.

Conclusions: Lymphedema and capillary malformation can occur together in the same extremity. Both conditions independently cause limb overgrowth primarily because of subcutaneous adipose deposition. Compression garments and suction-assisted lipectomy can improve the condition. Lymphedema-capillary malformation should not be confused with other vascular malformation overgrowth diseases that have different morbidities and treatments. (Plast Reconstr Surg Glob Open 2016;4:e618; doi: 10.1097/GOX.0000000000000487; Published online 10 February 2016.)

\footnotetext{
From the *Department of Plastic and Oral Surgery, and tDepartment of Radiology, Vascular Anomalies Center, Lymphedema Program Boston Children's Hospital, Harvard Medical School, Boston, Mass.

Received for publication March 9, 2015; accepted July 17, 2015.

Copyright (C) 2016 The Authors. Published by Wolters Kluwer Health, Inc. on behalf of The American Society of Plastic Surgeons. All rights reserved. This is an open-access article distributed under the terms of the Creative Commons Attribution-Non Commercial-No Derivatives License 4.0 (CCBY-NC-ND), where it is permissible to download and share the work provided it is properly cited. The work cannot be changed in any way or used commercially.

DOI: 10.1097/GOX.0000000000000487
}

he field of vascular anomalies is confusing because lesions often look similar, and incorrect terminology commonly is used. Diagnosis of a vascular anomaly is most difficult when a patient has multiple or combined lesions. The purpose of this study was to describe the rare combination of primary lymphedema associated with a capillary malformation of the lower extremity. These patients are typically labeled erroneously with a vascular

Disclosure: The authors have no financial interest to declare in relation to the content of this article. The Article Processing Charge was paid for by the authors. 
malformation overgrowth syndrome (eg, KlippelTrenaunay syndrome and Parkes Weber syndrome). Recognition of lymphedema-capillary malformation is important so that the patient is managed correctly.

\section{METHODS}

Our Vascular Anomalies Center and Lymphedema Program databases were queried for patients with both lower extremity primary lymphedema and capillary malformation. Diagnosis was made by history, physical examination, and imaging studies. Because lymphedema-capillary malformation has phenotypical overlap with other conditions clinically (eg, diffuse capillary malformation with overgrowth; congenital, lipomatous, overgrowth, vascular malformations, epidermal nevi and spinal/skeletal anomalies and/or scoliosis; Klippel-Trenaunay syndrome; and Parkes Weber syndrome), only patients who had imaging studies (eg, lymphoscintigraphy, magnetic resonance imaging [MRI], and computed tomography) confirming their diagnosis were included in the analysis. Clinical features, radiological findings, morbidity, and treatment were recorded.

\section{RESULTS}

Eight patients (4 females and 4 males) had confirmed lymphedema-capillary malformation(Figs. 1, 2 ). Nine other patients likely had the condition but did not have adequate photographs and/or imaging studies to ensure the diagnosis. The disease was unilateral in 6 patients and bilateral in 2 individuals. Patients were referred with a diagnosis of Klippel-Trenaunay syndrome $(\mathrm{n}=4)$, diffuse capillary malformation with overgrowth $(\mathrm{n}=3)$, or lymphatic malformation $(n=1)$. Morbidity included infection $(n=6)$, difficulty fitting clothes $(n=6)$, bleeding or leaking vesicles $(n=5)$, leg length discrepancy $(n=4)$, and difficulty ambulating $(\mathrm{n}=3)$. All patients were managed with compression garments, and 7 individuals were prescribed pneumatic compression. Operative intervention was liposuction $(n=3)$, treatment of phlebectatic veins $(\mathrm{n}=3)$, staged skin/subcutaneous excision $(n=1)$, and/or epiphysiodesis $(n=1)$.

\section{DISCUSSION}

Patients with vascular anomalies often are misdiagnosed and receive incorrect management. ${ }^{1,2}$
A

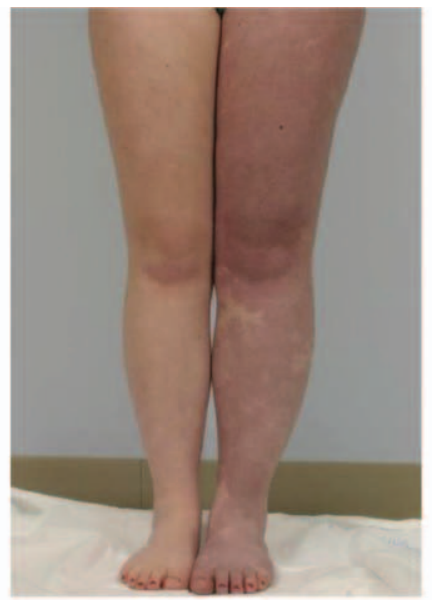

B

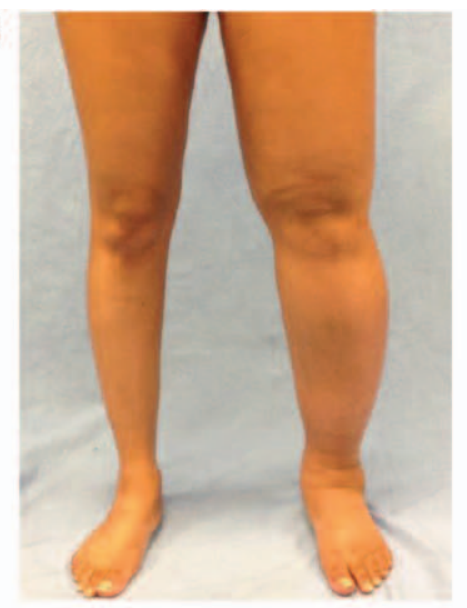

C

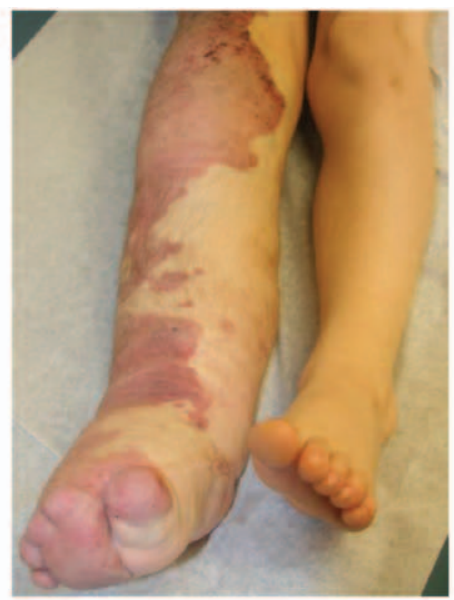

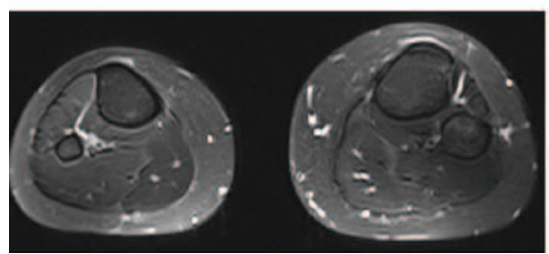
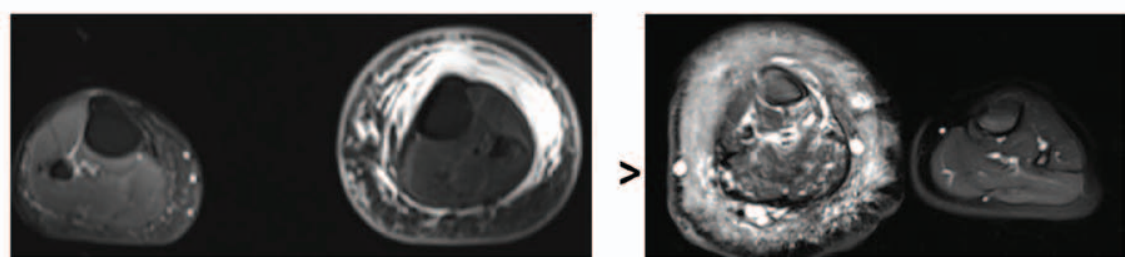

Fig. 1. Vascular malformations with phenotypical similarities to lymphedema-capillary malformation. A, Adult female with diffuse capillary malformation with overgrowth (DCMO) who had an epiphysiodesis of the left lower extremity. MRI illustrates increased subcutaneous adipose deposition with venous phlebectasia. B, Adult female with primary lymphedema of the left leg. MRI shows subcutaneous adipose hypertrophy and edema. C, Patient with Klippel-Trenaunay syndrome of the lower extremity. MRI indicates vascular malformations affecting all structures of the limb. The subcutaneous tissue contains microcystic lymphatic malformation, a persistent embryonal vein laterally (marginal vein of Servelle), and enlarged saphenous veins medially. The subfascial compartment contains venous malformations of the muscles and bone. Arrowhead identifies the marginal vein of Servelle. 

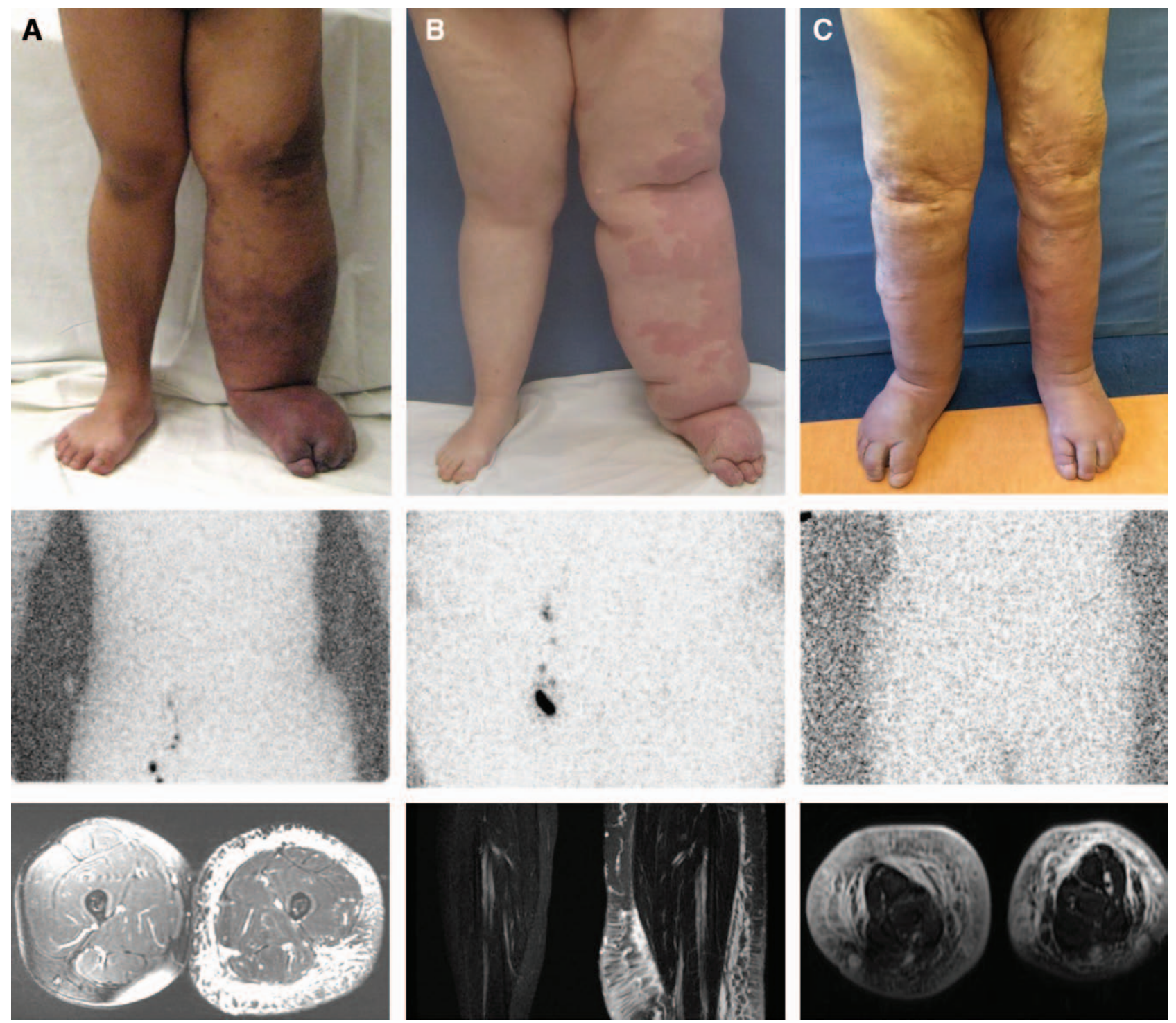

Fig. 2. Phenotypes of lymphedema-capillary malformation. A, Adolescent male with unilateral disease originally referred with "Klippel-Trenaunay syndrome." Lymphoscintigraphy shows the absence of tracer uptake in inguinal nodes 8 hours after injection (normal transit time is 45 minutes). Axial MRI exhibits subcutaneous adipose deposition and edema; structures below the muscle fascia are normal, and embryonal veins are not present. B, Adolescent female with left lower extremity involvement initially labeled with "diffuse capillary malformation with overgrowth." Lymphoscintigraphy illustrates no radiolabeled tracer in inguinal nodes 2 hours after injection. Coronal MRI indicates subcutaneous adipose hypertrophy and edema; the muscles and the bones are not affected. C, Sixty-one-year-old man with bilateral lymphedema-capillary malformation, who carried a diagnosis of "Klippel-Trenaunay syndrome" over the course of his life. Lymphoscintigraphy indicates absent transit of tracer to the bilateral inguinal nodes 2 hours after injection of radiolabeled colloid into the feet. MRI indicates enlargement of the subcutaneous compartment with edema and phlebectasia.

Although many types of vascular anomalies can cause lower extremity overgrowth, children frequently are labeled generically with "lymphedema" if there is no skin discoloration" ${ }^{3}$ or with "Klippel-Trenaunay syndrome" if a cutaneous stain is present. ${ }^{4,5}$ In this study, we describe the association of primary lower extremity lymphedema in combination with a capillary malformation.
Primary lymphedema results from the anomalous development of the lymphatic system and is rare, affecting 1 in 100,000 persons; several mutations are known to cause the disease. ${ }^{6,7}$ Males typically present with bilateral lower extremity swelling in infancy; females most commonly develop unilateral leg edema in adolescence. ${ }^{8}$ Lymphatic fluid in the interstitial space causes the extremity to enlarge 
PRS Global Open • 2016

\section{Enlarged Lower Extremity With Cutaneous Stain And Pitting Edema}

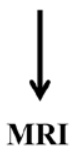

- Increased subcutaneous adipose and edema

- No embryonal veins, venous malformations, macro/microcystic lymphatic malformations

- Normal appearing subfascial tissues

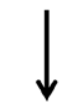

Lymphoscintigram

Delayed transit of tracer to inguinal nodes

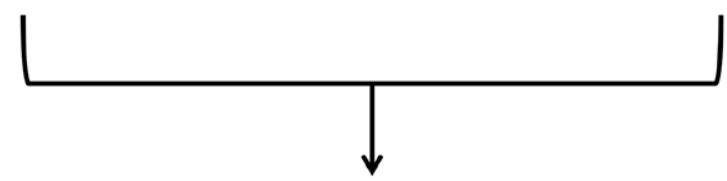

Lymphedema-Capillary Malformation

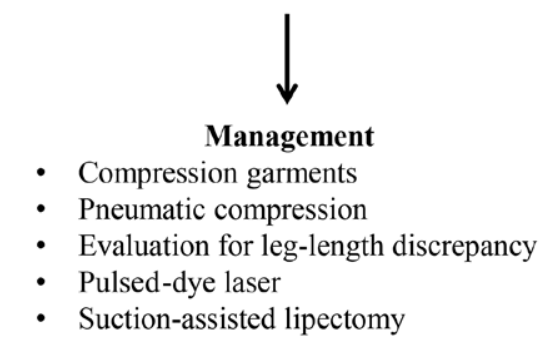

Fig. 3. Diagnosis and management of lymphedema-capillary malformation.

because of subcutaneous adipose deposition. ${ }^{9}$ Children with the disease may be erroneously diagnosed with Klippel-Trenaunay syndrome or Parkes Weber syndrome. ${ }^{3}$ Patients with lymphedema can have psychosocial morbidity because of their deformity and an increased risk of infection. ${ }^{8,10}$ Primary lymphedema usually can be diagnosed by history and physical examination. The color of the integument appears normal; patients have pitting edema of the distal limb, and the skin of the dorsal foot is unable to be pinched between 2 fingers. ${ }^{11,12}$ Diagnostic confirmation of lymphedema requires lymphoscintigraphy, which is $92 \%$ sensitive and $100 \%$ specific for the disease..$^{13,14}$

Capillary malformation (previously referred to as "port-wine stain") affects approximately 1 in 300 individuals; the lesion is caused by a somatic mutation in GNAQ. ${ }^{15,16}$ Rarely, a capillary malformation diffusely affects a large area of the lower extremity. Capillary malformation can cause tissues below the area of the stain to become overgrown, particularly subcutaneous adipose. ${ }^{4,17}$ Axial bone enlargement also can occur, resulting in a leg length discrepancy. ${ }^{4}$ Diagnosis of capillary malformation is made by physical examination. The stain darkens as the patient ages, and subcutaneous phlebectasia can develop as blood stagnates and dilates venules. Over time, capillary malformations become more similar to venous malformations histopathologically and radiological- ly. ${ }^{5,18,19}$ Patients with diffuse capillary malformation with overgrowth of the lower extremity often are erroneously labeled with "Klippel-Trenaunay syndrome" or "Parkes Weber syndrome." 4,5

Diagnostic confirmation of lymphedema-capillary malformation requires imaging (Fig. 3). If this condition is suspected based on history and physical examination, we then obtain an MRI and lymphoscintigraphy. We usually wait until children are at least 12 months of age to obtain the MRI to reduce the risk of anesthesia. Early diagnosis is important for prognosis and management and to rule out Klippel-Trenaunay or Parkes Weber syndrome. Lymphedema only affects the skin and subcutaneous tissues and does not cause axial overgrowth. However, the capillary malformation component might cause vertical bone hypertrophy and a leg length discrepancy. MRI shows that vascular anomalies are not present in tissues below the muscle fascia; this finding does not change over time. Other features of lymphedema-capillary malformation include subcutaneous edema (lymphedema), subcutaneous phlebectasia (capillary malformation), and excess adipose hypertrophy below the skin (lymphedema and capillary malformation). Although MRI can exhibit features consistent with lymphedema (thickened skin, subcutaneous edema and adipose hypertrophy, normal subfascial compartment), diagnostic confirmation requires lymphoscintigraphy. Lymphoscintigraphic 
Table 1. Characteristics of Lymphedema-Capillary Malformation and Other Lower Extremity Overgrowth Conditions

\begin{tabular}{|c|c|c|c|c|c|}
\hline & $\begin{array}{c}\text { Lymphedema- } \\
\text { Capillary } \\
\text { Malformation }\end{array}$ & Lymphedema & $\begin{array}{c}\text { Capillary } \\
\text { Malformation }\end{array}$ & $\begin{array}{c}\text { Klippel- } \\
\text { Trenaunay }\end{array}$ & $\begin{array}{l}\text { Parkes } \\
\text { Weber }\end{array}$ \\
\hline Cutaneous stain & + & - & + & + & + \\
\hline Subcutaneous adipose overgrowth & + & + & + & - & - \\
\hline Subcutaneous edema & + & + & - & - & - \\
\hline Venous malformations & - & - & - & + & - \\
\hline $\begin{array}{l}\text { Microcystic/macrocystic lymphatic } \\
\text { malformations }\end{array}$ & - & - & - & + & - \\
\hline Arteriovenous shunting & - & - & - & - & + \\
\hline Subfascial vascular malformations & - & - & - & + & + \\
\hline Embryonal vein & - & - & - & + & - \\
\hline Abnormal lymphoscintigraphy & + & + & - & _- & - \\
\hline Leg length discrepancy & + & - & + & + & + \\
\hline Mutation & unkown & $\begin{array}{l}\text { VEGFR3, SOX18, } \\
\text { FOXC2 }\end{array}$ & $G N A Q$ & PIKЗCA & RASA1 \\
\hline
\end{tabular}

findings consistent with lymphatic dysfunction include delayed transit time, dermal backflow, and/or abnormal collateral vessels. . $^{13,14}$

The major differential diagnosis of lymphedema-capillary malformation is Klippel-Trenaunay syndrome or Parkes Weber syndrome (Table 1). Individuals with Klippel-Trenaunay syndrome have a capillary-lymphatic-venous malformation of an overgrown extremity. ${ }^{20}$ The condition is caused by a somatic mutation in PIK3CA. ${ }^{21}$ The "capillary" malformation of the leg typically is a lymphatic malformation with bleeding vesicles that cause lymphorrhea. In contrast, a sporadic capillary malformation caused by a $G N A Q$ mutation does not have vesicles. Some patients with lymphedema-capillary malformation in our series seemed to have a sporadic capillary malformation without evidence of lymphatic etiology, whereas others had a stain that contained lymphatic vesicles. Children with Klippel-Trenaunay syndrome may have an enlarged contralateral foot and exhibit macrodactyly. Klippel-Trenaunay syndrome has venous and/or lymphatic malformations that affect tissues below the muscle fascia., ${ }^{4,5,19,20}$ A large embryonic vein in the subcutaneous tissue (marginal vein of Servelle) is present and pathognomonic for the condition ${ }^{4,5}$; diversion venography usually demonstrates an intact deep venous system. Endovenous laser ablation of the marginal vein and coil occlusion of the sciatic vein are performed to prevent thromboembolism. Individuals with Klippel-Trenaunay syndrome require monitoring for a leg length discrepancy and may need a shoe lift or epiphysiodesis. Patients often undergo selective amputations to facilitate footwear. Reduction of circumferential overgrowth typically is performed using staged skin and subcutaneous excision. ${ }^{20}$ Cutaneous lymphatic vesicles are managed by sclerotherapy, carbon dioxide laser, and/or resection. Deeper lymphatic and venous anomalies may benefit from sclerotherapy.

Parkes Weber syndrome consists of a combination of a capillary malformation and diffuse arteriovenous malformation of an extremity causing overgrowth. ${ }^{20}$ The capillary malformation is consistent with a sporadic lesion or with capillary malformation-arteriovenous malformation; they typically do not bleed or cause lymphorrhea. The cutaneous stain is warmer than a typical capillary malformation and exhibits fast-flow by Doppler; the lesion may be phenotypically similar to an arteriovenous malformation. The syndrome can be sporadic or familial as a result of a mutation in RASA $1 .{ }^{22}$ The tissue below the muscle fascia is affected, and the muscle and bone usually are overgrown. ${ }^{19,20}$ MRI exhibits diffuse subfascial microfistulae represented as flow-voids. ${ }^{19}$ The enlarged limb muscles and bones show abnormal signal and enhancement. Angiography illustrates dilated, tortuous arteries and draining veins with discrete arteriovenous shunting. ${ }^{19}$ Individuals with Parkes Weber syndrome require monitoring for a leg length discrepancy. Patients occasionally need intervention for congestive heart failure and embolization to reduce shunting. Amputation may be necessary.

It is important to differentiate lymphedemacapillary malformation from Klippel-Trenaunay and Parkes Weber syndromes because the prognosis and treatment are different. Lymphedemacapillary malformation exhibits morbidity of both lymphedema and capillary malformation: infection (lymphedema), vesicles (lymphedema), difficulty ambulating (lymphedema), leg length discrepancy (capillary malformation), phlebectasia (capillary malformation), circumferential overgrowth (lymphedema and capillary malformation), and difficulty fitting clothes (lymphedema and capillary malformation). The condition is managed similar to pa- 
tients with either isolated lymphedema or capillary malformation. Individuals are prescribed customfitted garments and pneumatic compression to treat lymphedema. ${ }^{8,10,12}$ Pulsed dye laser is considered to lighten the color of the capillary malformation. Because both lymphedema and capillary malformation cause subcutaneous adipose overgrowth, patients with lymphedema-capillary malformation have circumferential enlargement of their lower extremity. Individuals in our series generally had larger extremities compared with patients with either isolated lymphedema or capillary malformation, possibly because the 2 conditions synergistically increased adipose hypertrophy. Although lymphedema does not cause axial skeletal overgrowth, diffuse capillary malformation can cause a leg length discrepancy. Four of the patients in our series had a leg length discrepancy, and thus, children with lymphedemacapillary malformation should undergo orthopedic screening. Patients with symptomatic overgrowth can be treated with suction-assisted lipectomy to reduce the size of their extremity; this intervention is used to manage patients with isolated lymphedema or capillary malformation. ${ }^{8,10,12}$ Because lower extremity capillary malformations cause phlebectasia, patients may require intervention for symptomatic varicosities. None of the patients with lymphedema-capillary malformation had interventions that are commonly required for Klippel-Trenaunay syndrome or Parkes Weber syndrome (eg, removal of embryonic veins, embolization, amputations, and treatment of macrodactyly).

It is unclear whether patients with lymphedemacapillary malformation have both conditions as a coincidence or whether the 2 vascular malformations are embryologically related. Capillary malformation is caused by a somatic mutation in GNAQ, whereas primary lymphedema may result from several mutations (eg, VEGFR3, SOX18, and FOXC2). ${ }^{7,16}$ We hypothesize that lymphedema-capillary malformation likely results from an anomaly that causes both hypoplastic lymphatic development and capillary malformation. Patients with lymphedemacapillary malformation might have a novel somatic mutation responsible for their condition. Alternatively, lymphedema-capillary malformation may be a phenotypic variant of primary lymphedema or an overgrowth condition with a known mutation (eg, GNAQ, PIK3CA, and RASA1).

Arin K. Greene MD, MMSc

Department of Plastic and Oral Surgery Boston Children's Hospital 300 Longwood Ave, Boston, MA 02481 E-mail: arin.greene@childrens.harvard.edu

\section{REFERENGES}

1. Greene AK, Liu AS, Mulliken JB, et al. Vascular anomalies in 5,621 patients: guidelines for referral. JPediatr Surg. 2011;46:1784-1789.

2. Hassanein AH, Mulliken JB, Fishman SJ, et al. Evaluation of terminology for vascular anomalies in current literature. Plast Reconstr Surg. 2011;127:347-351.

3. Schook CC, Mulliken JB, Fishman SJ, et al. Differential diagnosis of lower extremity enlargement in pediatric patients referred with a diagnosis of lymphedema. Plast Reconstr Surg. 2011;127:1571-1581.

4. Lee MS, Liang MG, Mulliken JB. Diffuse capillary malformation with overgrowth: a clinical subtype of vascular anomalies with hypertrophy. J Am Acad Dermatol. 2013;69:589-594.

5. Uihlein LC, Liang MG, Fishman SJ, et al. Capillaryvenous malformation in the lower limb. Pediatr Dermatol. 2013;30:541-548.

6. Smeltzer DM, Stickler GB, Schirger A. Primary lymphedema in children and adolescents: a follow-up study and review. Pediatrics. 1985;76:206-218.

7. Boon LM, Ballieux F, Vikkula M. Pathogenesis of vascular anomalies. Clin Plast Surg. 2011;38:7-19.

8. Schook CC, Mulliken JB, Fishman SJ, et al. Primary lymphedema: clinical features and management in 138 pediatric patients. Plast Reconstr Surg. 2011;127:2419-2431.

9. Brorson H, Ohlin K, Olsson G, et al. Adipose tissue dominates chronic arm lymphedema following breast cancer: an analysis using volume rendered CT images. Lymphat Res Biol. 2006;4:199-210.

10. Maclellan RA, Couto RA, Sullivan JE, et al. Management of primary and secondary lymphedema: analysis of 225 referrals to a center. Ann Plast Surg. 2015;75:197-200.

11. Stemmer R. [A clinical symptom for the early and differential diagnosis of lymphedema]. Vasa 1976;5:261-262.

12. Maclellan RA, Greene AK. Lymphedema. Semin Pediatr Surg. 2014;23:191-197.

13. Gloviczki P, Calcagno D, Schirger A, et al. Noninvasive evaluation of the swollen extremity: experiences with 190 lymphoscintigraphic examinations. J Vasc Surg. 1989;9:683-689; discussion 690.

14. Szuba A, Shin WS, Strauss HW, et al. The third circulation: radionuclide lymphoscintigraphy in the evaluation of lymphedema. J Nucl Med. 2003;44:43-57.

15. Jacobs AH, Walton RG. The incidence of birthmarks in the neonate. Pediatrics. 1976;58:218-222.

16. Shirley MD, Tang H, Gallione CJ, et al. Sturge-Weber syndrome and port-wine stains caused by somatic mutation in GNAQ. NEngl J Med. 2013;368:1971-1979.

17. Greene AK, Taber SF, Ball KL, et al. Sturge-Weber syndrome: soft-tissue and skeletal overgrowth. J Craniofac Surg. 2009;20 (Suppl 1):617-621.

18. Gupta A, Kozakewich H. Histopathology of vascular anomalies. Clin Plast Surg. 2011;38:31-44.

19. Arnold R, Chaudry G. Diagnostic imaging of vascular anomalies. Clin Plast Surg. 2011;38:21-29.

20. Kulungowski AM, Fishman SJ. Management of combined vascular malformations. Clin Plast Surg. 2011;38:107-120.

21. Kurek KC, Luks VL, Ayturk UM, et al. Somatic mosaic activating mutations in PIK3CA cause CLOVES syndrome. Am J Hum Genet. 2012;90:1108-1115.

22. Revencu N, Boon LM, Mulliken JB, et al. Parkes Weber syndrome, vein of Galen aneurysmal malformation, and other fast-flow vascular anomalies are caused by RASA1 mutations. Hum Mutat. 2008;29:959-965. 